\title{
Over a Decade of recA and tly Gene Sequence Typing of the Skin Bacterium Propionibacterium acnes: What Have We Learnt?
}

\author{
Andrew McDowell \\ Northern Ireland Centre for Stratified Medicine, School of Biomedical Sciences, Ulster University, \\ Londonderry BT47 6SB, UK; a.mcdowell@ulster.ac.uk
}

Received: 14 November 2017; Accepted: 19 December 2017; Published: 21 December 2017

\begin{abstract}
The Gram-positive, anaerobic bacterium Propionibacterium acnes forms part of the normal microbiota on human skin and mucosal surfaces. While normally associated with skin health, P. acnes is also an opportunistic pathogen linked with a range of human infections and clinical conditions. Over the last decade, our knowledge of the intraspecies phylogenetics and taxonomy of this bacterium has increased tremendously due to the introduction of DNA typing schemes based on single and multiple gene loci, as well as whole genomes. Furthermore, this work has led to the identification of specific lineages associated with skin health and human disease. In this review we will look back at the introduction of DNA sequence typing of $P$. acnes based on $r e c A$ and tly loci, and then describe how these methods provided a basic understanding of the population genetic structure of the bacterium, and even helped characterize the grapevine-associated lineage of $P$. acnes, known as P. acnes type Zappe, which appears to have undergone a host switch from humans-to-plants. Particular limitations of $r e c A$ and tly sequence typing will also be presented, as well as a detailed discussion of more recent, higher resolution, DNA-based methods to type P. acnes and investigate its evolutionary history in greater detail.
\end{abstract}

Keywords: Propionibacterium acnes; recA; tly; typing; phylogenetics; horizontal gene transfer; multiplex PCR; MLST; SLST; ribotyping; MLVA; whole genome sequencing

\section{Introduction:}

Propionibacterium acnes is a Gram-positive anaerobic bacterium and member of the 'cutaneous' group of human propionibacteria on the skin, although it can also be isolated from the oral cavity as well as the genitourinary and gastrointestinal tracts [1]. The organism is an opportunistic pathogen associated most notably with the common skin condition acne vulgaris after which it is named [2]. Acne is an inflammatory disease of the pilosebaceous follicle affecting the face, chest and back, primarily during adrenarche (Figure 1).

Over the last 20 years, however, there has been an increasing recognition that we may have significantly underestimated the role of this bacterium in other human infections and clinical conditions. From the scientific literature, we now have a large body of evidence associating this bacterium with infections of indwelling medical devices, especially shoulder prostheses, as well as sarcoidosis, prostate cancer, back pain and fatal granuloma after soft tissue trauma [3-7]; further work is, however, required to prove whether the bacterium actually plays a role in the development of some of these conditions, especially lumbar disc herniation and prostate disease.

Within the last decade, we have also seen significant advances in our understanding of the intraspecies phylogeny of P. acnes. Distinct phylogroups have been discovered, and specific strains or sequence types (ST) associated with human health or disease revealed [8-12]. In this review we will initially focus on how DNA sequence typing schemes based on $r e c A$ and tly loci were used to reveal 
the basic underlying phylogenetic structure of $P$. acnes. Specific issues or caveats with $\operatorname{rec} A$ and $t l y$ sequence typing will then be highlighted, alongside a detailed description of newer, high resolution, molecular typing methods that have been developed to characterize the bacterium and better detail its phylogeny.

(A)

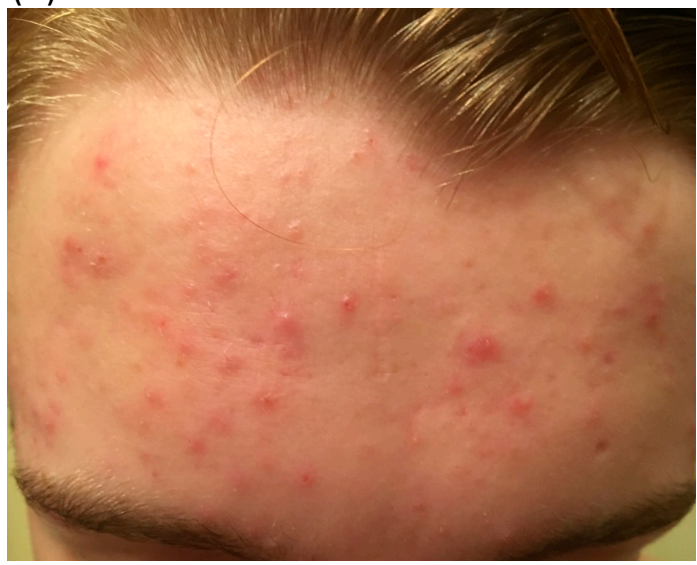

(B)

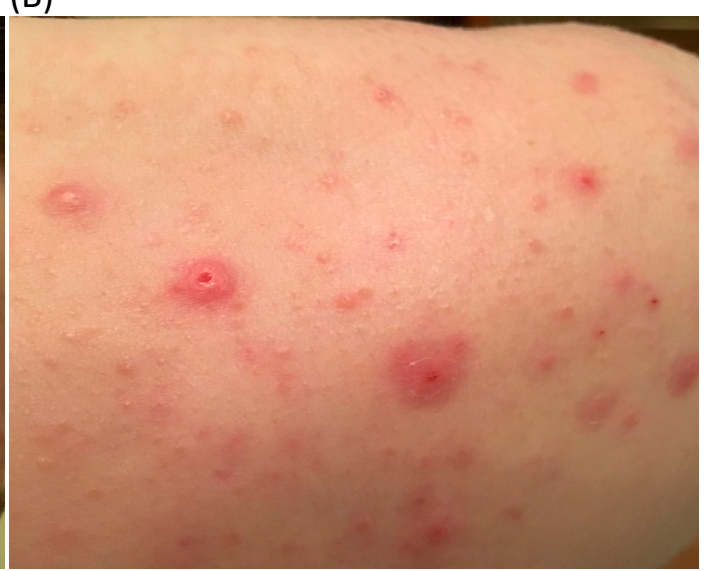

Figure 1. Moderate inflammatory and non-inflammatory acne lesions on the forehead (A) and shoulder (B) of a 14-year-old adolescent boy.

\section{Introduction of $\operatorname{rec} A$ and $t l y$ Gene Sequencing for Phylogenetic Analysis of P. acnes}

Gene sequence analysis of $P$. acnes based on the non-ribosomal housekeeping (HK) gene recA (1047 bp; PPA1012) and the putative haemolysin/FtsJ-like methyltransferase gene tly (777 bp; PPA1396) was first described in 2005 as part of a larger study investigating the phylogenetic relationship between the two serotypes of P. acnes, known as types I and II [8]. Analysis of these genetic loci revealed that types I and II represented highly distinct phylogenetic groupings or divisions within the species. It also revealed further phylogenetic sub-divisions within the type I clade, designated types IB and IC, which displayed atypical reactions with monoclonal antibodies $(\mathrm{mAb})$ originally developed for the identification of type I (QUBPa1) and type II (QUBPa2) strains [8,11,13]. Both antibodies, which target antigenically variable cell surface adhesins that bind dermatan sulphate (DsA1; DsA2) (QUBPa1) and a glycolipid-containing antigen (QUBPa2), show no significant reaction with the type IB lineage, but do react with type IC strains $[8,11,14]$; other type I strains, designated type IA, react with QUBPa1 but not QUBPa2. Recently, the DsA1 protein has also been shown to bind human fibrinogen [15]. Interestingly, just five months after the description of the $\operatorname{rec} A$ and tly sequencing results, Cohen et al. [5] described three distinct pulsed field gel electrophoresis (PFGE) groups of P. acnes isolated from cancerous prostate tissue. We now know these pulsogroups actually correspond to the rec $A$ and tly types IA, IB and II [11,12]; in the same study, sequencing of the transcarboxylase $12 S$ gene could differentiate pulsogroups I (type IA) and II (type IB) from group III (type II), but could not further subtype the type I clade. In 2008, application of rec $A$ gene sequencing was also instrumental in the identification of a new phylogenetic division within P. acnes, which was designated recA type III [9]. Strains of the type III clade, which were originally isolated from spine intervertebral disc material and now also human skin, have the capacity to form a filamentous-like cell morphology not observed with types I and II, and are also non-reactive with QUBPa1 and QUBPa2.

\section{Choice of $\operatorname{rec} A$ and tly Loci for Phylogenetic Analysis}

The recA gene was chosen by McDowell et al. [8] since it is a valuable phylogenetic marker in bacterial systematics, and classifications based on rec $A$ have proved to be robust and consistent with those obtained by using rRNA genes [16]. Furthermore, protein-encoding HK genes can often 
provide greater phylogenetic resolution of very closely related organisms compared to the 16S rRNA gene due to a higher molecular clock speed, thereby generating a larger pool of informative sites for phylogenetic reconstructions [17]. Consistent with this, in the case of types I and II only one type-specific polymorphism at position 827 was identified within the $16 \mathrm{~S}$ gene of the strains selected for analysis, versus 10 type-specific differences in $\operatorname{rec} A$ [8]. The rec $A$ gene has also been successfully used for inter- and intra-species differentiation of organisms of the Burkholderia cepacia complex, Agrobacterium spp. and for typing of Vibrio cholerae isolates [18-21].

In the case of the tly gene, it was selected for analysis since it had a putative function as a cell surface/extracellular haemolysin/cytotoxin. In contrast to HK gene loci, such genes are often under strong positive selection for non-synonymous mutations and recombinational events by the host immune system leading to rapid diversification and increased discriminatory power for finer scale typing [22]; such 'hyper-variable' genes are often used to investigate very recent patterns of descent (short term epidemiology) and used as a complement to Multilocus Sequence Typing (MLST) analysis, as well as providing valuable information on the evolution of virulence loci. In the case of the tly gene, however, no clear evidence for diversifying selection exists upon analysis of multiple allele sequences, and this locus appears to have co-evolved with HK genes potentially indicating an important role in commensal existence for the bacterium $[11,12]$. The observation that the Tly protein family now needs to be redefined as an RNA-binding FtsJ-like methyltransferase involved in ribosomal biogenesis may be important in this context, indicating a dual function as a HK gene alongside a role as a haemolysin $[12,23]$. The tly gene is also present in other human propionibacteria, including P. avidum, P. humerusii and the recently described species P. namnetense [24].

\section{Adoption of recA and tly Gene Sequencing as a Typing Tool for P. acnes}

Prior to the description of $r e c A$ and tly sequencing analysis of P. acnes, typing methods for the bacterium focused on fermentation, phage and serological reactions, DNA macrorestriction profiling by PFGE and Random Amplification of Polymorphic DNA analysis [25-29]. Soon after publication, researchers started to adopt $r e c A$ and $t l y$-based sequencing as a moderate resolution typing method, with the genes being utilized individually for single locus sequence typing (SLST), or concatenated for multilocus analysis. These genes have been used as typing tools to investigate whether the different phylogroups of P. acnes are associated with specific human infections or clinical conditions, including prosthetic joint and dental infections, sarcoidosis, prostate cancer and lumbar disc herniations highlighted earlier [30-36]. These sequence-based typing methods have also been used to genetically characterize P. acnes strains isolated from healthy human stomach mucosa [37]. Such studies started to provide initial evidence that differences may indeed exist in the association of specific phylogroups with disease, including strains of type IB and II with prosthetic joint infections and type I and II with prostate cancer. In addition to disease associations, characterization of $P$. acnes strains based on their rec $A$ and tly phylogenies has provided a framework onto which intraspecies genomic and proteomic characteristics can be mapped [38,39], as well as a broad range of putative virulence, biochemical and immunological properties $[8,9,13,31,32,40]$. A good example is the production of DsA1 and DsA2 adhesins by strains of type IA and IC, but not IB, II or III, and the differential production of CAMP-factors, in particular the abundant production of CAMP factor 1 by type IB and II strains, but not type IA [13,39]. Collectively, such studies started to reveal differences in pathogenic potential between phylogroups and their association with human disease.

\section{5. recA and tly Gene Sequencing to Characterise P. acnes Type Zappe Strains}

$\operatorname{rec} A$ and tly gene sequence analysis has even been used to characterize strains of the grapevine-associated $P$. acnes lineage known as P. acnes type Zappe [41]. This new type of $P$. acnes appears to have adapted to an endophytic lifestyle, and is believed to have arisen from a human-to-plant interkingdom bacterial transfer approximately 7500 years ago during the domestication of grapevines [41]. Interestingly, although P. acnes type Zappe forms a distinct 
phylogenetic cluster from P. acnes upon $16 \mathrm{~S}$ rDNA analysis, it groups with $P$. acnes type I strains based on recA and tly sequences. These discordant gene trees are likely to result from incomplete lineage sorting due to recent diversification. Furthermore, unlike $P$. acnes, the rec $A$ gene in $P$. acnes type Zappe appears to have lost its function during this unusual host switching event, possibly reflecting endosymbiosis, leading to the accumulation of a large number of non-synonymous mutations; in comparison, the tly and $16 \mathrm{~S}$ rRNA genes of P. acnes type Zappe are much more conserved. These gene sequence characteristics, along with the detection of $P$. acnes type Zappe within plant tissues (bark, pith and fibres of Xylem vessels), provides evidence to support the endophyte nature of this bacterium and tight symbiosis with the plant.

\section{Taxonomic Legacy}

When the $r e c A$ and tly typing methods were first described, our understanding of the underlying population genetic structure of $P$. acnes was poor. The identification of distinct genetic divisions and sub-divisions therefore provided a platform for more in depth study of the phylogenetic and taxonomic heterogeneity of $P$. acnes, and how this related to human health and disease. This has ultimately led to the recent proposal of the type I, II and III phylogroups as distinct subspecies known as P. acnes subsp. acnes, P. acnes subsp. defendens and P. acnes subsp. elongatum, respectively based on phylogenetic, genomic, phenotypic differences, as well as associations with different types of infections and clinical conditions including acne, progressive macular hypomelanosis $(\mathrm{PMH})$, and prosthetic joint and soft tissue infections $[42,43]$. The cutaneous propionibacteria have now also been recently proposed as a novel genera, known as Cutibacterium, with P. acnes renamed as Cutibacterium acnes [44].

\section{7. recA and tly Alleles Provide Hints of Conjugal Transfer of Large DNA Segments}

The subsequent development of more recent molecular typing methods for P. acnes based on multilocus sequence typing (MLST) schemes (discussed later) combined with the growing number of available whole genome sequences, has provided newer, high resolution methods for detailed scrutiny of the population genetic structure of the bacterium. This has revealed much greater levels of phylogenetic structure within the type I phylogroup, enabling additional differentiation of strains into types $\mathrm{IA}_{1}$ and $\mathrm{IA}_{2}$, alongside the type IB and IC groups, and identification of clonal complexes (CC) and singleton strains $[10-12,43,45,46]$. These high-resolution MLST and whole genome sequencing (WGS) methods have, however, also revealed caveats with $\operatorname{rec} A$ and tly sequencing, since the combination of $\operatorname{rec} A$ and tly allele sequences originally used to identify the type IB phylogroup have now also been found in a subset of clearly defined type $\mathrm{IA}_{1}$ strains from CC4 (MLST 8 nomenclature), all strains from the $\mathrm{IA}_{2}$ lineage, and the aberrant type $\mathrm{IA}_{1}$ singleton strain SK187 which displays a mosaic of genes found in other type I lineages, including type IB [10,14,38,45].

This is illustrated in Figure 2A, which demonstrates phylogenetic clustering of strains crossing these different genetic distances based on concatenated rec $A$ and tly gene sequences (1824 bp) (the same clustering of strains is seen with single rec $A$ and tly trees; Figure S1), yet clear, non-overlapping clustering of these phylogroups when high resolution $\mathrm{MLST}_{8}$ analysis is applied (Figure 2B). These results help to explain why a sub-set of strains presumptively identified as type IB based on $\operatorname{rec} A$ and tly analysis displayed reaction with the type IA mAb QUBPa1 [11,14].

$P$. acnes has a clonal population structure and is in linkage disequilibrium [11,12]. The organism has a high degree of sequence conservation, although recombination events are still evident in the history of the bacterium. Due to this, P. acnes is a candidate organism for the development of phylogenetically accurate SLST schemes. Interestingly, phylogenetic network analyses reveals only the tly sequences conforming to a very clear tree-like structure, although the Phi test for recombination is not statistically significant for either loci (Figure 3). Furthermore, phylogenetic trees based on the analysis of the individual genes are congruent (Figure S1). The discovery of linked alleles across different phylogenetic lineages does, however, suggest conjugal transfer and homologous recombination of very large DNA segments; these genes comprise a genomic fragment that stretches to at least $420 \mathrm{Kbp}$ (KPA171202 
coordinates 1095280-1515117). This scenario would help to explain why rec $A$ and tly sequences generate congruent phylogenies.

Further support also comes from the identification of camp5 (KPA171202 coordinates 1305348-1306193) and gms (KPA171202 coordinates 1503535-1504578) alleles that are also shared between $\mathrm{CC} 4$ and types $\mathrm{IA}_{2}$ and IB, and located within the same segment [10]. Collectively, this would tentatively suggest that multiple conjugation events of unusually large chromosomal replacements have shaped the genome dynamics of the type I clade; such large chromosomal replacements have also been observed with Staphylococcus aureus and Streptococcus agalactiae $[47,48]$. While such events are assumed to be rare due to the large size of the fragments, they may have had a dramatic effect on the evolution of the bacterium. More detailed sequence-based analyses will, however, be required to confirm this possibility. Alongside this, P. acnes has a flexible gene pool with the presence and absence of different island-like genomic regions with aberrant $\mathrm{G}+\mathrm{C}$ content and flanking insertion sequences that encode putative virulence factors and traits potentially associated with fitness and niche adaptation $[38,49,50]$.

Rates of recombination also appear to differ throughout the population, and the association of alleles appears less significant when distinct phylogroup populations are considered [11,12]. Reduced rates of recombination between the different subsp. of P. acnes may indicate ecological differences within the body since members of the same habitat are more likely to undergo recombination events (sympatric speciation) [51]. Against this background, it is interesting that only type II strains have an active CRISPR/Cas system, making type I and III strains potentially more susceptible to horizontal gene transfer (HGT) of fitness and virulence traits [46,52].

(A)

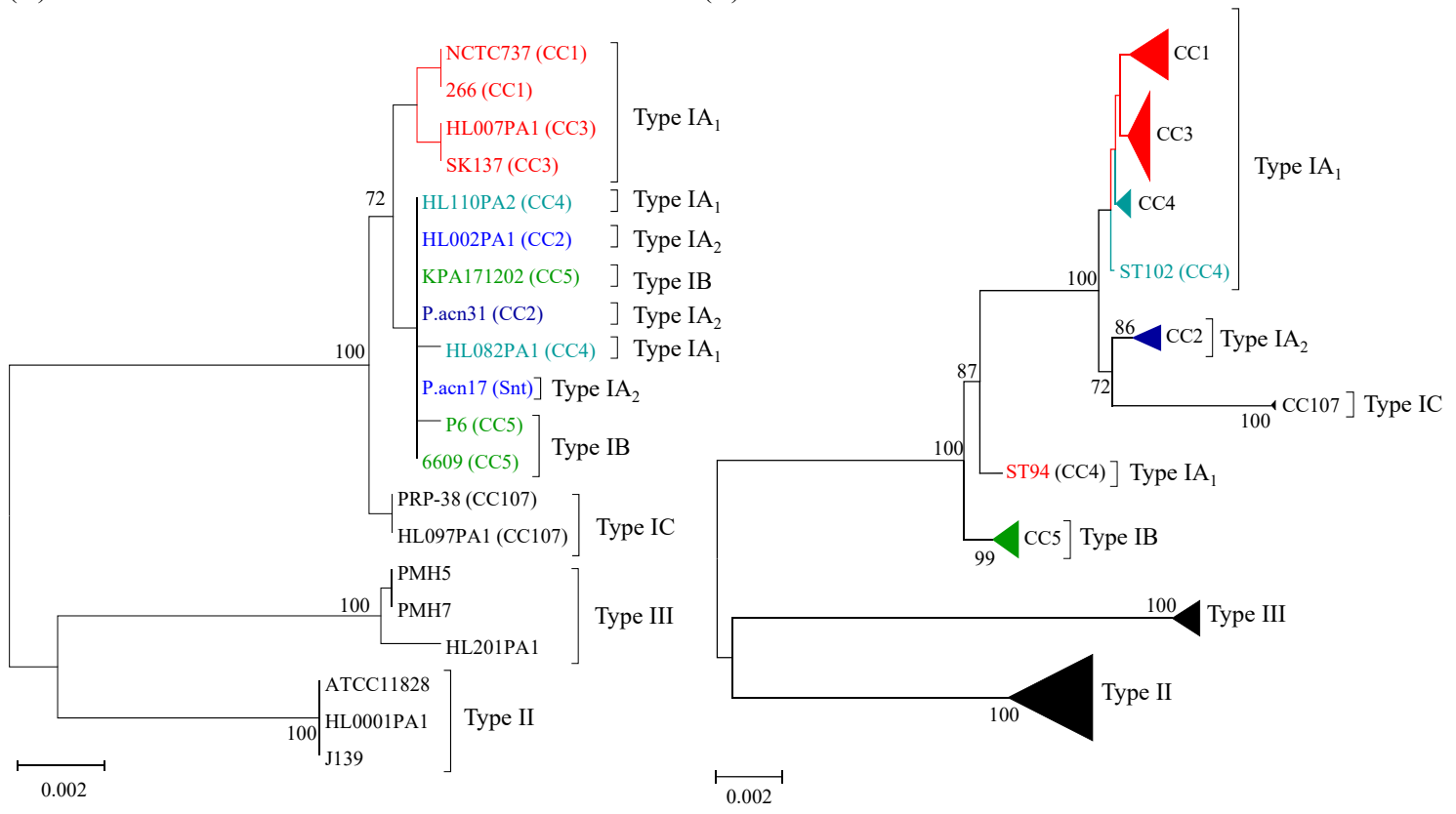

Figure 2. Minimum evolution phylogenetic trees of concatenated $\mathrm{rec} A$ and tly sequences (1824 bp) from isolates selected to represent all known phylogroups (A), and concatenated gene sequences (4235 bp) from all current STs in the MLST 8 database (B); the latter is updated from [43] with STs. Bootstrapping statistics were performed using 500 data sets, and only bootstrap values $\geq 70 \%$ are shown. Clonal complexes (CC) are indicated. An overlapping cluster of strains from CC4 (type $\mathrm{IA}_{1}$ ), CC2 (type $\mathrm{IA}_{2}$ ) and CC5 (type IB) can clearly be seen based on analysis of recA and tly sequences (A), but on $\mathrm{MLST}_{8}$ analysis strains from these different phylogroups form separate, distinct clusters with high bootstrap values $(\mathbf{B})$. 
(A)

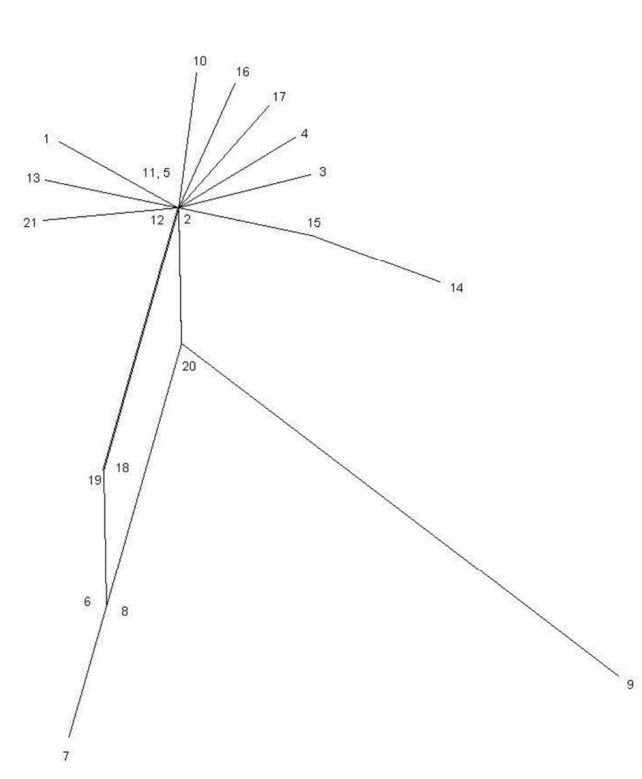

(B)

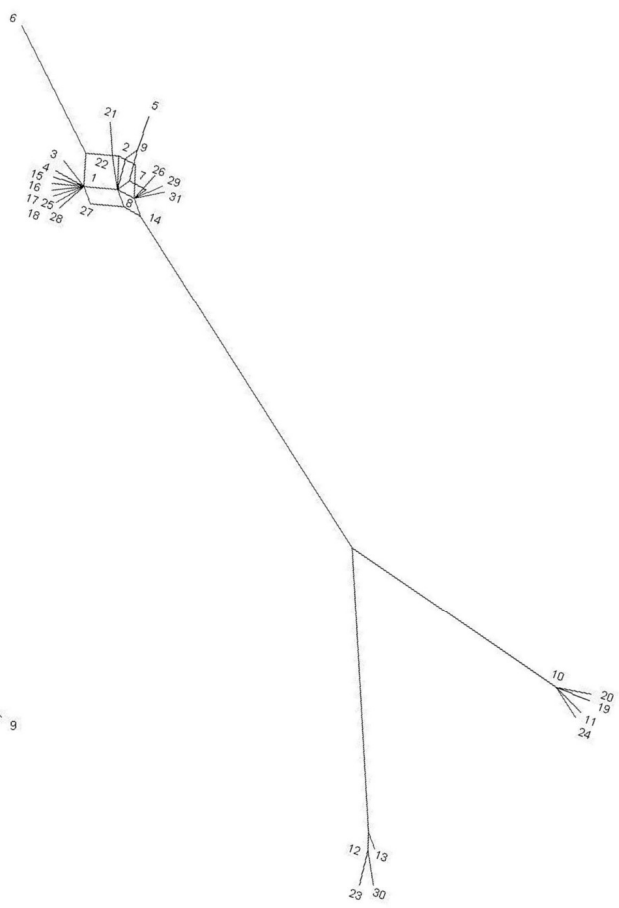

Figure 3. Split decomposition analysis of all current $\operatorname{rec} A(\mathbf{A})$ and $t l y(\mathbf{B})$ allele sequences. rec $A$ allele sequences $\left(753 \mathrm{bp}\right.$ ) were taken from the $\mathrm{MLST}_{9}$ database [53] and tly allele sequences (777 bp) from the MLST $_{8}$ database [54]; the latter is updated from [12] with new allele sequences. No evidence of statistically significant recombination was identified in either genes using the Phi test $(p=0.135$ for $r e c A ; p=0.735$ for $t l y$ ), although some interconnected pathways were present.

\section{Newer Molecular Typing Methodologies for Propionibacterium acnes}

As the $\operatorname{rec} A$ and tly loci cannot reliably identify type IB strains from those related to the type $\mathrm{IA}_{1}$ sub-clade corresponding to $\mathrm{CC} 4$, or strains of type $\mathrm{IA}_{2}$, their application as a typing tool has limitations; the methods are still valid, however, for the identification of almost all other type $\mathrm{IA}_{1}$ strains, as well as those from the type IC, II and III phylogroups. Since the $r e c A$ and tly sequencing approaches were originally reported over 10 years ago, a wide range of newer DNA-based typing methods have been described with distinct advantages and disadvantages to one another; most of these are still superior to the original $r e c A$ and tly typing methods in terms of its moderate resolving power. These key methods include:

\subsection{MLST Schemes}

MLST is based on indexing genetic variation within multiple HK genes, normally seven [55]. Unique alleles for each loci are given an arbitrary number, and the different combinations of these alleles, known as the allelic profile, assigned a ST number. The allelic profile therefore does not take into consideration the number of nucleotide differences between alleles, and this lack of weighting in regard to sequence divergence helps to correct for HGT events which can distort phylogenetic signals [55]. In addition to concatenated DNA sequence analysis which provides minimal information of ancestry or patterns of descent, MLST enables isolates to also be grouped or clustered based on sharing a defined number of alleles (usually $\geq 6 / 7$ ) with at least one other member of the group, thus generating non-overlapping CCs and predicting founding genotypes. This type of analysis, which is performed using an algorithm such as eBURST, provides the opportunity to infer appropriate patterns of evolutionary descent between isolates over short timescales [56].

Two independent MLST schemes and associated, publically available, databases for P. acnes have now been developed based on completely different sets of protein-encoding gene loci $[10,11]$. 
These schemes provide high resolution typing of the bacterium and generate phylogenies which are essentially congruent with those based on WGS analysis. One scheme highlighted earlier in the review, and based on the analysis of eight loci (MLST $84253 \mathrm{bp}$ ), was originally developed at the University of Warwick and then modified by researchers at Queen's University, Belfast to include the camp2 and tly genes [11] (Figure 2B); the database for this scheme can be found at Propionibacterium acnes MLST Databases [54]. A second scheme, which was based on nine loci and corresponding amplification and sequencing primers developed at the University of Bath, was fully adopted by researchers at Orebro University (4536 bp) [57]. Researchers at Aarhus University also utilized this method but replaced the cob gene with $r e c A$ (known as $\mathrm{MLST}_{9} ; 4233 \mathrm{bp}$ ) and also developed a database for the scheme which can be found at Multi Locus Sequence Typing [53]. Both MLST 8 and MLST 9 schemes are generally concordant in how they cluster strains into different CCs, but some differences do exist in the resolution of particular strains within these CCs. These CC equivalencies and specific strain differences have been detailed elsewhere [11]. At the time of writing, the $\mathrm{MLST}_{8}$ database comprises 127 distinct STs with nine CCs superimposed on a background of 19 singletons in sequence space (Figure 4). The $\mathrm{MLST}_{9}$ database comprises 125 STs.

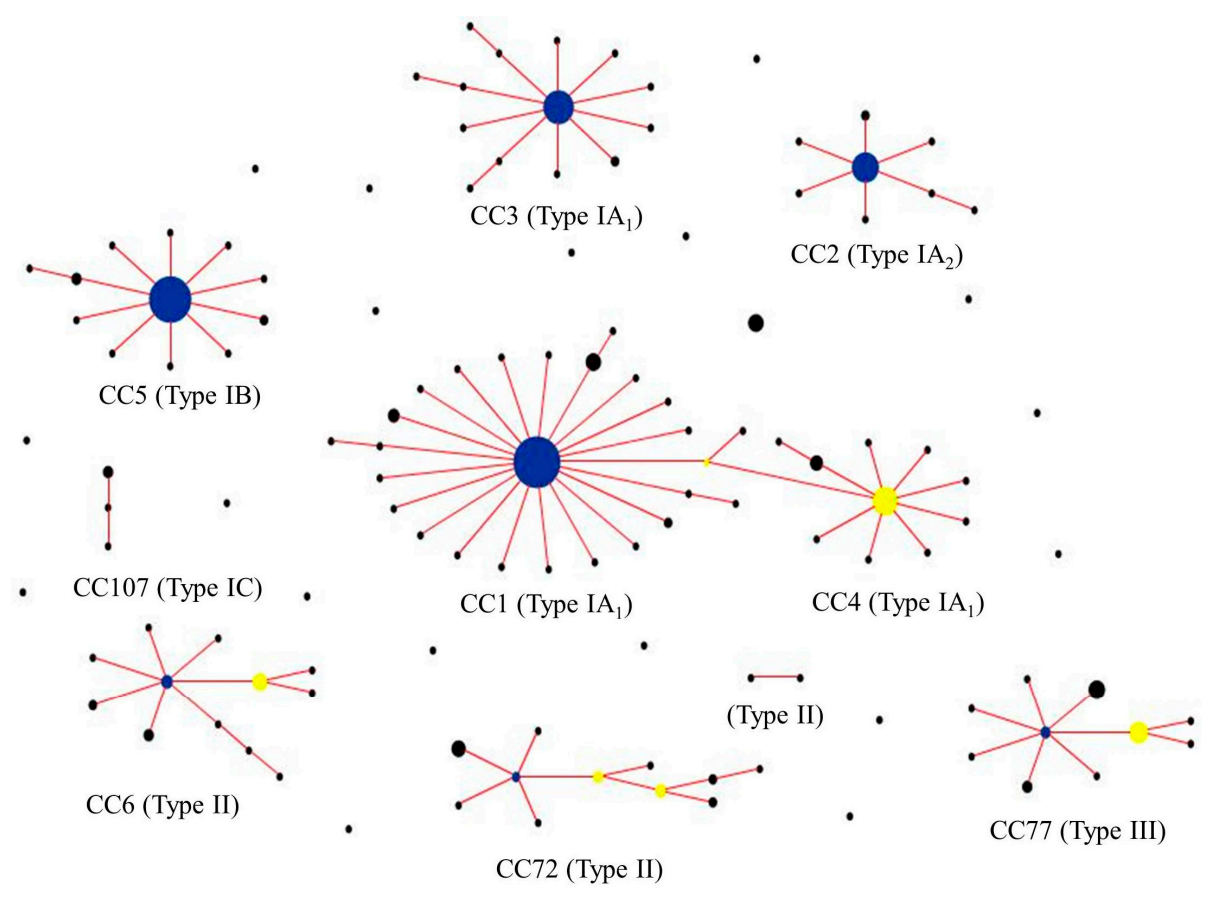

Figure 4. eBURST population snapshot of the current $P$. acnes $\mathrm{MLST}_{8}$ database. To date, a total of nine clonal complexes, where the isolates share $7 / 8$ loci with at least one other ST in the group, and 19 singletons have been identified from the analysis of over 400 isolates. Founding genotypes are highlighted in blue and sub-founders in yellow. The frequency of each ST is indicated by circle size.

Being a DNA-sequencing based method, MLST offers portability over gel-based typing approaches, and is an extremely valuable and stable system for global epidemiology and genetic population studies. Indeed, using these methods we and others have shown that $P$. acnes has an epidemic population structure, with highly successful clonal lineages that are globally disseminated [e.g., ST1 and ST3 (type IA 1 ), ST2 (type $\mathrm{IA}_{2}$ ) and ST5 (type IB) based on $\mathrm{MLST}_{8}$ analysis] within the human population [11,12] (Figure 5); some of these epidemic lineages appear to be permanent members of the skin microbiota and are associated with acne [11,12]. 


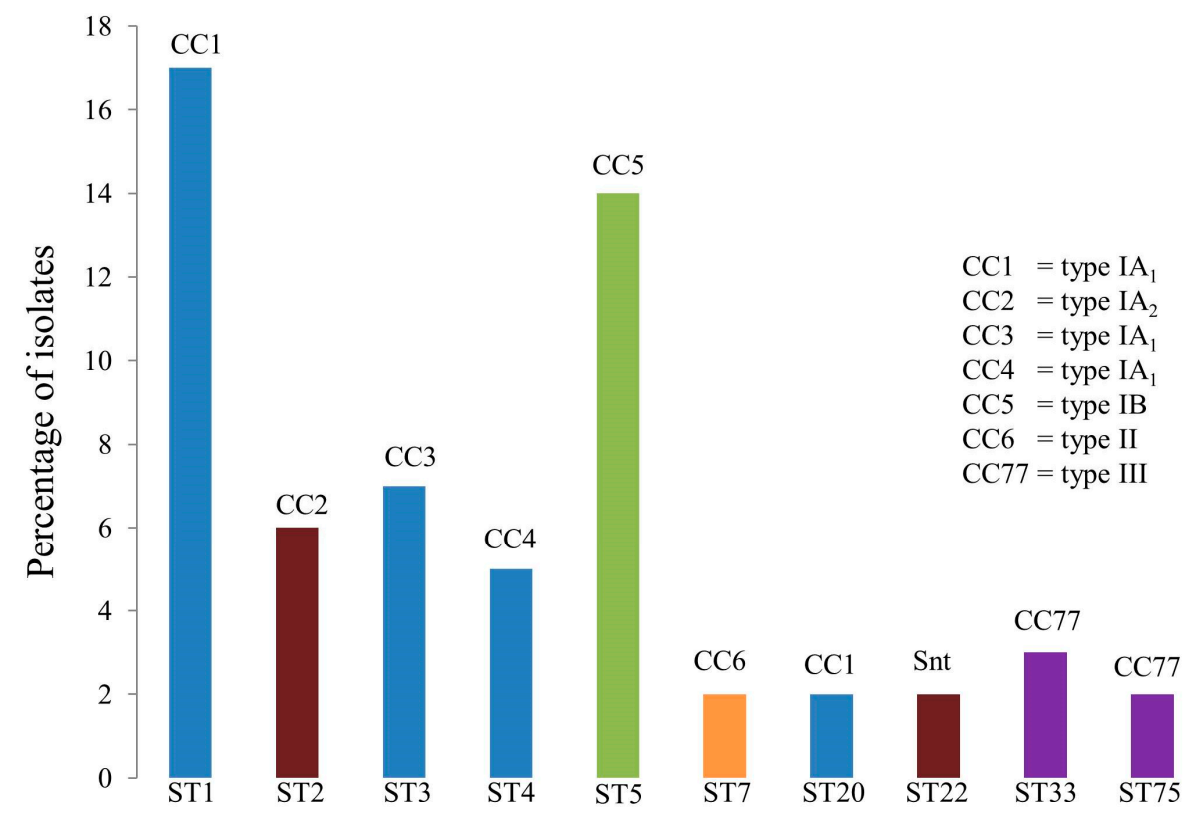

Figure 5. Current top 10 most populous STs within the P. acnes $\mathrm{MLST}_{8}$ isolate database. Clonal complexes (CC) are also indicated.

Despite all its advantages, the key downsides of MLST are its labor and time consuming nature as well as expense, especially when analyzing large numbers of isolates. In an attempt to circumvent these problems, and to streamline the MLST workflow, it has been shown that only four of the eight $\mathrm{MLST}_{8}$ gene loci (aroE, guaA, camp2, tly) need to be sequenced to correctly predict phylogroup, CC and in most cases ST from the full MLST profiles available in the database [12]. This is only possible because of the clonal nature of $P$. acnes, and the relatively limited number of genotypes that are found.

\subsection{Multiplex PCR}

A set of three separate PCR assays for phylogroup typing of $P$. acnes was originally described in 2006 by Shannon et al. [58]; this method was only capable of resolving type IA, IB and II strains, providing no data on type $\mathrm{IA}_{1}, \mathrm{IA}_{2}$, IC or type III status. More recently, a multiplex touchdown PCR typing method for $P$. acnes isolates that provides unambiguous identification of all the main phylogroups (type $\mathrm{IA}_{1}, \mathrm{IA}_{2}, \mathrm{IB}, \mathrm{IC}$, II and III) in a single reaction has been described [59]. The method utilizes six primer sets that target the $16 \mathrm{~S}$ rRNA gene to confirm species identify (all isolates), ATPase (types $\mathrm{IA}_{1}, \mathrm{IA}_{2}$, and IC), sodA (types $\mathrm{IA}_{2}$ and IB), atpD (type II), and recA (type III) HK genes, as well as a Fic family toxin gene (type IC); the HK loci on which the multiplex assay was developed are from the $\mathrm{MLST}_{8}$ scheme where multiple alleles of each gene are available for analysis and identification of type-specific single nucleotide polymorphisms (SNPs) for primer design. Phylogroup identification is based on the visual pattern of reaction with the different primer sets. The key advantage of this 6-plex PCR assay is that it provides a rapid, high-throughput, and technically undemanding typing method for epidemiological and phylogenetic investigations. The multiplex assay also provides a simple way to identify potentially novel taxa due to atypical or non-typeable PCR patterns that could arise, for example, when new alleles or allele combinations are encountered in new STs. A limitation of the multiplex method is that it only resolves isolates to the phylogroup level; if very high resolution typing is required then other methods, such as MLST or WGS, should be carried out. These latter methods, however, only provide significantly more information for type $\mathrm{IA}_{1}$ and type II phylogroups due to their greater genetic heterogeneity and deeper level of phylogenetic structure relative to types $\mathrm{IA}_{2}, \mathrm{IB}, \mathrm{IC}$, and III. In the latter case, the phylogroups represent relatively tight phylogenetic clusters 
(only one CC for each phylogroup) with a limited number of STs, some of which are highly dominant in the population and widely disseminated (Figures 4 and 5).

The multiplex assay has now been described for the typing of $P$. acnes isolates from patients with acne [60-62], PMH [63], wound exudates and abscesses [62], microdiscectomy tissue [64], central nervous system and prosthetic joint infections [65], and other clinical conditions [60]. It has also been used for high throughput typing of $P$. acnes isolates from the pre-operative skin and surgical wound of patients undergoing spinal operations; this study was a large randomized controlled trial investigating the effects of povidone-iodine-alcohol (PVI) and chlorhexidine gluconate-alcohol on surgical wound contamination compared to PVI alone [66]. The validation of the multiplex method by a number of independent groups has led to the conclusion that it is a robust and valid method for P. acnes typing [62].

\subsection{Ribotyping}

A ribotyping scheme for $P$. acnes, based on analysis of the $16 \mathrm{~S}$ rRNA gene $(\sim 1450 \mathrm{bp}$; positions 29-to-1483 bp), has been described by Fitz Gibbon et al. [46]; novel ribotypes (RT) in this SLST scheme were assigned based on at least one unique SNP. Upon Sanger sequencing of amplicons obtained from genomic DNA pooled from pilosebaceous units ('pores') on the nose of acne and control subjects, more than 11K RTs were identified, although only a very small number appear abundant in the skin with the minor RTs representing singletons. Compared to RT1, the most abundant of the RTs, all other defined RTs have $\geq 99 \%$ sequence identify which is in keeping with the highly conserved nature of the $16 \mathrm{~S}$ rRNA locus at the intraspecies level. Despite this, the limited number of SNPs available can differentiate the main type I, II and III phylogroups from one another, as well as type $\mathrm{IA}_{1}$ from $\mathrm{IA}_{2}$ strains which have unique RTs in keeping with their distinct phylogenies (Table 1).

Table 1. Correlation between ribotypes, phylogroups and MLST CCs.

\begin{tabular}{cccc}
\hline & & MLST $_{\mathbf{8}}$ & MLST $_{\mathbf{9}}$ \\
\hline Ribotype & Phylogroup & Clonal Complex & Clonal Complex \\
$1,5,532$ & IA $_{1}$ & CC1 & CC18 \\
$1,4,5$ & IA $_{1}$ & CC3 & CC3 \\
8 & IA $_{1}$ & CC4 & CC31 \\
3,16 & IA $_{2}$ & CC2 & CC28 \\
1 & IB & CC5 & CC36 \\
5 & IC & CC107 & Singletons \\
2,6 & II & CC6/CC72 & CC60 \\
9 & III & CC77 & ND \\
\hline
\end{tabular}

Within the type $\mathrm{IA}_{1}$ clade, strains corresponding to CC4 by $\mathrm{MLST}_{8}$ analysis (equivalent to CC31 by $\mathrm{MLST}_{9}$ ) can also be resolved, but a limitation of the method is that strains from CC1 and CC3 by MLST 8 analysis (equivalent to CC18 and CC3, respectively by $\mathrm{MLST}_{9}$ ), as well as type IB and IC strains, cannot be separated as they share RT1 and RT5 (Table 1). As the ribotyping approach has specific strain resolution limitations, this is the main disadvantage to its use. As it is only based on one locus, the data is also not amenable to allelic profile clustering. It does, however, significantly reduce Sanger sequencing costs compared to MLST analysis of isolates while retaining the advantage of DNA sequence portability and stability between laboratories. Currently, there is no public database for the P. acnes ribotyping scheme.

\subsection{High Resolution SLST (HR-SLST)}

The development of a high resolution SLST (HR-SLST) scheme for P. acnes is clearly desirable since it would reduce the expense and workflow involved in MLST analysis, alongside its ability to directly analyze complex biological samples for $P$. acnes population structure. While P. acnes is an appropriate 
choice for the development of such a method, the low level of genetic variability found amongst the HK genes of this clonal organism does make such a task difficult. To address this issue, Scholz et al. [67] utilized novel python scripts to 'mine' the available whole genome sequences of all known $P$. acnes phylogroups, and identify sufficiently variable target loci on which a novel SLST scheme could be developed. This computational analysis pinpointed a 483-497 bp sequence which differentiated strains to a level of resolution approaching that obtained by MLST (Figure 6, Table S1); although the pattern of phylogroup clustering within the type I clade varies somewhat from that obtained by MLST and WGS analysis. This sequence is located immediately upstream of the CAMP factor 1 gene (PPA1340), and partially overlaps with a number of hypothetical genes [67]. The success of this locus suggests that recombination events are extremely limited in its history, and this is confirmed by phylogenetic network analysis which shows a tree-like structure, and a non-significant Phi test for recombination (Figure 7). The SLST method uses a letter and number-based nomenclature for ST assignment and a database for the scheme can be found at SLST for Cutibacterium acnes (formerly Propionibacterium acnes) [68].

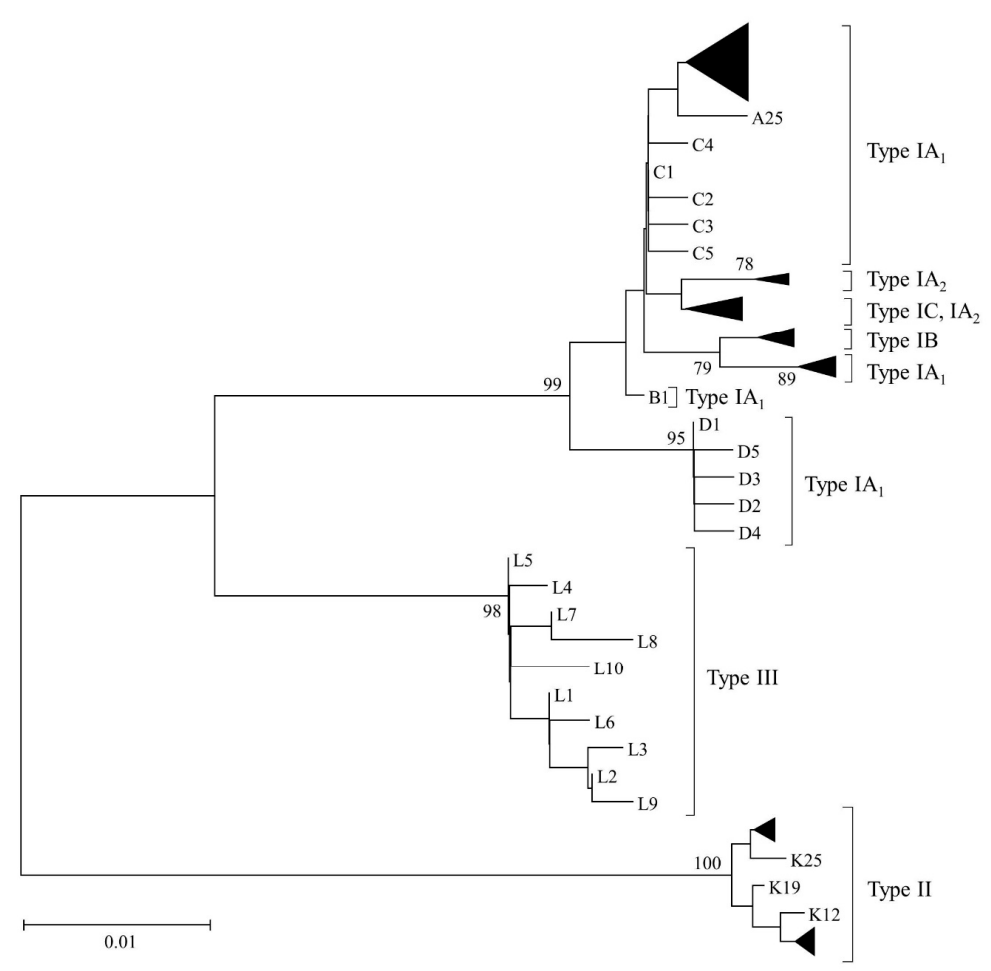

Figure 6. Minimum evolution tree of the current 112 STs from the 483-497 bp HR-SLST target locus. Sequences are from the SLST database at SLST for Cutibacterium acnes (formerly Propionibacterium acnes) [68]. Bootstrapping statistics were performed using 500 data sets, and only bootstrap values $\geq 70 \%$ are shown.

In addition to isolate analysis, the SLST method has also been used to examine the P. acnes community structure within skin swab samples taken from various body sites of a healthy individual [67] and patients with PMH [69] via Roche 454 pyrosequencing, which provides reads sufficiently long to cover the target sequence; this metagenomic approach enables mixed strain populations of the bacterium to be analyzed. The method can, however, be adapted to run on other next generation sequencing (NGS) platforms, such as Illumina using pair-end reads $(2 \times 300 \mathrm{bp})$. Similar to ribotyping, the SLST approach will reduce Sanger sequencing costs compared to MLST, and is a portable and stable system, although as it is only based on one locus the data is also not amenable to allelic profile clustering. 


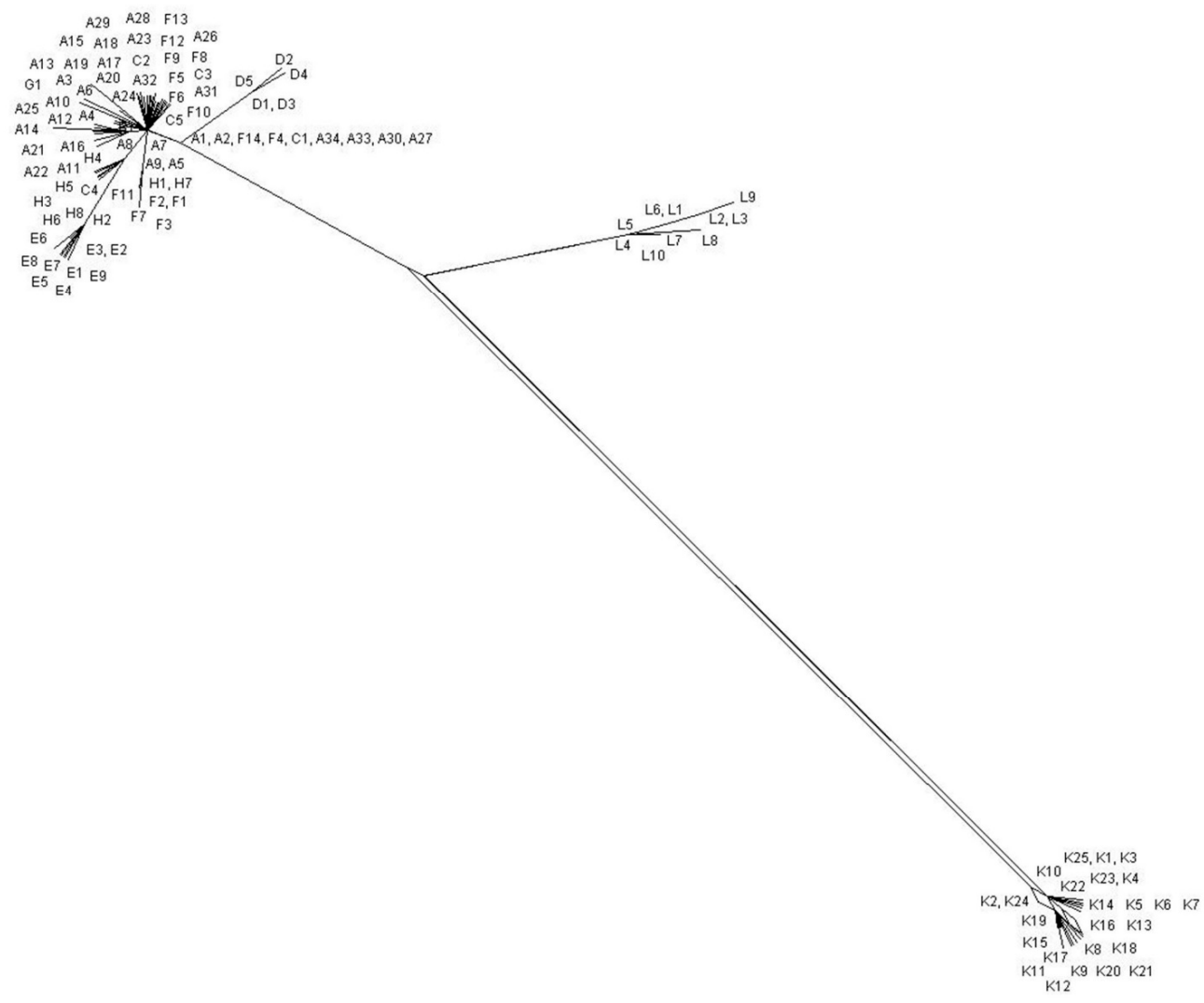

Figure 7. Split decomposition analysis of all current SLST allele sequences (483-497 bp) from the HR-SLST database [68]. No evidence of statistically significant recombination was identified using the Phi test $(p=0.399)$. Updated from [59] with new allele STs.

\subsection{Multiple Locus Variable Number of Tandem Repeat (VNTR) Analysis (MLVA)}

MLVA is a typing method for bacteria that is based on the variable number of tandem repeats (VNTR) present in multiple loci. These hypervariable loci are short sequences of repetitive DNA that arise due to slipped strand mispairing during DNA replication, and frequently vary between strains from the same species. An MLVA scheme for P. acnes based on the analysis of 13 VNTRs (MLVA 13 ) has been described by Hauck et al. [70]. These included 10 large VNTRs with repeat units ranging from 14-31 bp, and three small VNTRs with 6 bp size repeats. Like MLST, MLVA generates an allelic profile which in this case corresponds to the number of repeats at each locus, and a specific MLVA type number. The selected VNTR markers in P. acnes are present in genes that include putative HtaA domain and adhesin proteins, fibrinogen- and penicillin-binding proteins and hypotheticals, as well as an intergenic region [70]. With the MLVA $_{13}$ scheme, clustering of P. acnes isolates was found to be in good agreement with phylogenies based on WGS analysis, although a small number of discrepancies were observed. An advantage of this method is that it is relatively cheap, fast and easy to perform but portability can be a significant issue when amplicons are sized as banding patterns by conventional electrophoresis [71]; this can be greatly improved by capillary electrophoresis on an automated DNA sequencing instrument. Another potential issue with this method is the stability of the VNTR markers, although the small VNTRs used in this scheme appear to be stable upon repeat testing [70]. To date, the $P$. acnes MLVA scheme is yet to be utilized by the wider research community. The P. acnes MLVA database is scheduled to be released shortly at MLVAbank for Microbes Genotyping [72]. 


\subsection{Whole Genome Sequencing}

High resolution MLST of $P$. acnes generates phylogenies that, in general, match those obtained by WGS analysis. When analyzing a large number of isolates, however, it is an expensive typing methodology, especially with Sanger sequencing costs which are generally in the range of $£ 3$-to- $£ 5$ per read depending on the service provider. As the costs of NGS have continued to fall, and are comparable per isolate to MLST, rapid and high quality WGS analysis of bacterial strains is now increasing common for epidemiological investigations [73,74].

Unlike traditional MLST which is normally based on seven loci, WGS provides the opportunity to develop scaled up core-genome MLST (cgMLST) schemes, or a whole-genome MLST (wgMLST) approach, where all the equivalent loci between isolates are compared (core + accessory); this is based on de novo assembly of sequences to a reference genome [75]. As an alternate to the gene-by-gene approach, the phylogenetic relationships between isolates can also be based on the analysis of differences in genome core SNPs, which offers fine resolution but requires a reference sequence; this method is based on mapping short reads to a reference genome. To date, over 120 P. acnes genomes have been completed or are at the draft stage [76], and both core SNP and cgMLST analysis (based on the concatenated sequence of $76 \mathrm{HK}$ genes) have been applied to this dataset to create whole genome trees $[38,43,45,46]$.

WGS is the ultimate typing tool providing information on the full gene complement and genomic rearrangements. The gene-by-gene approach does, however, enable a hierarchical approach to typing where the number of genes analyzed is selected on the level of resolution required. Ultimately, WGS will likely replace other current molecular methods of P. acnes typing as costs continue to decline and bench top NGS sequencers become commonplace; the genome is also relatively small for sequencing (2.5 Mbp). Furthermore, various online web servers now provide software that will generate MLST profiles from whole genome data, such as Bacterial Isolate Genome Sequence Database (BIGSdb) [77,78] and the Centre for Genomic Epidemiology [79]. A key issue to address moving forward, however, is agreement on the optimal number of genes to use for WGS typing of P. acnes while maintaining epidemiological concordance; this would help to standardize interlaboratory comparisons.

\section{Typing Algorithm}

The level of resolution required for a typing scheme depends on the epidemiological questions being addressed. For $P$. acnes we currently use the algorithm highlighted in Figure 8 as our normal approach to typing of the bacterium. For culture-based investigations, multiple colonies $(n=15-20)$ from a sample are rapidly pre-screened by multiplex PCR as a first line typing method, before a further subset of these isolates $(n=5)$ are analyzed by high resolution MLST/ SLST if required. This approach not only helps to estimate the degree of phylogroup heterogeneity within a sample, but also maximizes the number of genetically diverse isolates selected for additional high resolution typing while keeping costs down. For non-culture-based typing, we utilize HR-SLST for direct metagenomic analysis based on the Illumina MiSeq platform. This approach enables the relative abundance of different pylogroups and SLST genotypes within a sample to be determined, but is more technically demanding. 


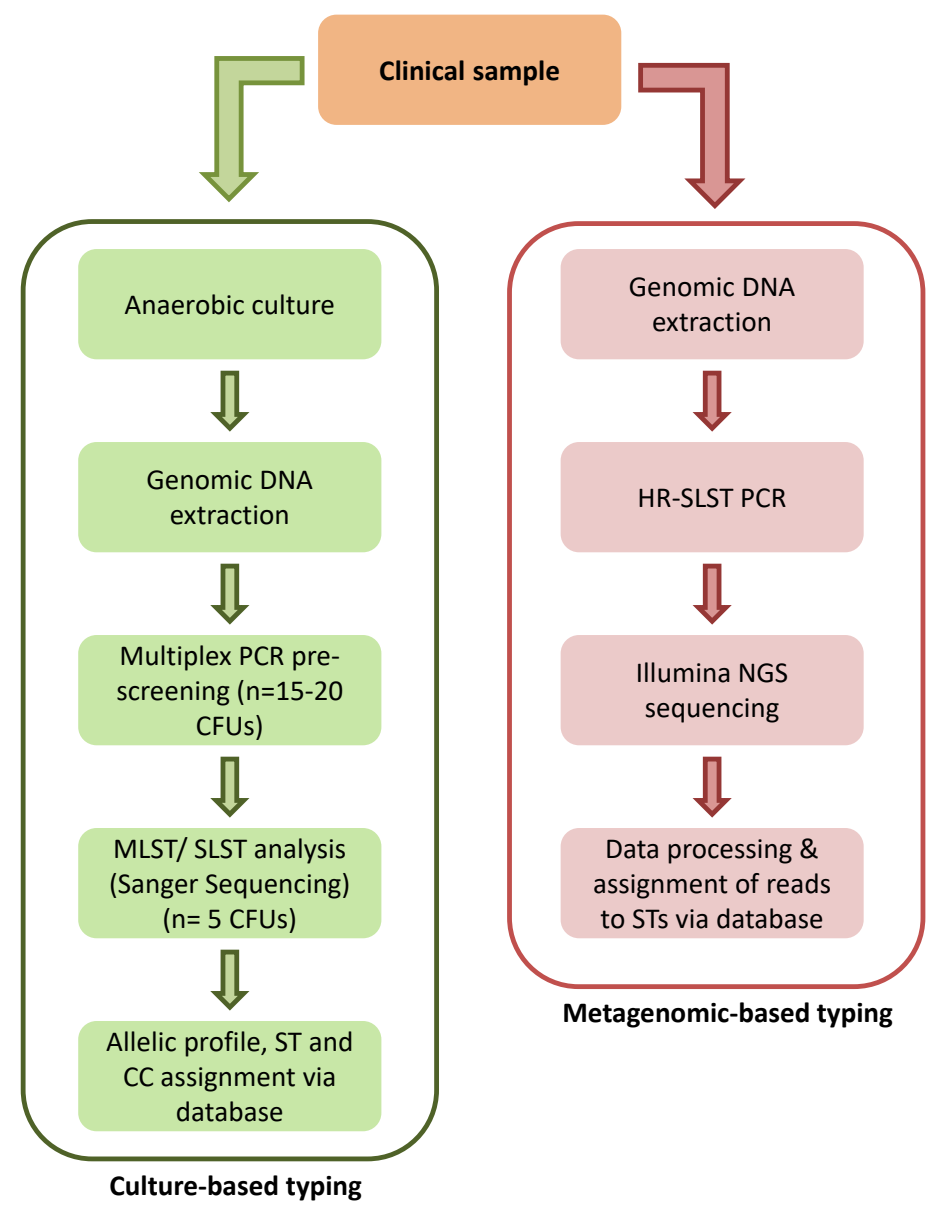

Figure 8. Algorithm for culture and non-culture-based typing pathways for P. acnes.

\section{Conclusions}

In conclusion, the introduction of rec $A$ and tly gene sequence typing of $P$. acnes over 10 years ago proved an important first step in dissecting the underlying phylogenetic structure of this bacterium and the association of different genetic groupings with human health and disease. Since then, many newer molecular-based typing methodologies for P. acnes have been introduced. In particular, multiplex PCR and MLST/ HR-SLST, either individually or combined, now represent popular choices for typing, providing valuable and accurate information of the genetic population structure of the bacterium within clinical samples.

Supplementary Materials: The following are available online at http:/ /www.mdpi.com/2076-2607/6/1/1/s1.

Acknowledgments: A.M. is funded under the European Union Regional Development Fund (ERDF) EU Sustainable Competitiveness Programme for N. Ireland \& the N. Ireland Public Health Agency (HSC R\&D).

Conflicts of Interest: The author declares no conflict of interest.

\section{References}

1. Patrick, S.; McDowell, A. Genus I. Propionibacterium. In Bergey's Manual of Systematic Bacteriology, 2nd ed.; Springer: New York, NY, USA, 2011; Volume 5, pp. 1138-1156. ISBN 978-0-387-95043-3.

2. Beylot, C.; Auffret, N.; Poli, F.; Claudel, J.-P.; Leccia, M.-T.; Del Giudice, P.; Dreno, B. Propionibacterium acnes: An update on its role in the pathogenesis of acne. J. Eur. Acad. Dermatol. Venereol. 2014, 28, 271-278. [CrossRef] [PubMed] 
3. Piper, K.E.; Jacobson, M.J.; Cofield, R.H.; Sperling, J.W.; Sanchez-Sotelo, J.; Osmon, D.R.; McDowell, A.; Patrick, S.; Steckelberg, J.M.; Mandrekar, J.N.; et al. Microbiologic diagnosis of prosthetic shoulder infection by use of implant sonication. J. Clin. Microbiol. 2009, 47, 1878-1884. [CrossRef] [PubMed]

4. Eishi, Y. Etiologic link between sarcoidosis and Propionibacterium acnes. Respir. Investig. 2013, 51, 56-68. [CrossRef] [PubMed]

5. Cohen, R.J.; Shannon, B.A.; McNeal, J.E.; Shannon, T.; Garrett, K.L. Propionibacterium acnes associated with inflammation in radical prostatectomy specimens: A possible link to cancer evolution? J. Urol. 2005, 173, 1969-1974. [CrossRef] [PubMed]

6. $\quad$ Albert, H.B.; Lambert, P.; Rollason, J.; Sorensen, J.S.; Worthington, T.; Pedersen, M.B.; Nørgaard, H.S.; Vernallis, A.; Busch, F.; Manniche, C.; et al. Does nuclear tissue infected with bacteria following disc herniations lead to Modic changes in the adjacent vertebrae? Eur. Spine J. 2013, 22, 690-696. [CrossRef] [PubMed]

7. Gao, T.W.; Li, C.Y.; Zhao, X.D.; Liu, Y.F. Fatal bacteria granuloma after trauma: A new entity. Br. J. Dermatol. 2002, 147, 985-993. [CrossRef] [PubMed]

8. McDowell, A.; Valanne, S.; Ramage, G.; Tunney, M.M.; Glenn, J.V.; McLorinan, G.C.; Bhatia, A.; Maisonneuve, J.F.; Lodes, M.; Persing, D.H.; et al. Propionibacterium acnes I and II represent phylogenetically distinct groups. J. Clin. Microbiol. 2005, 43, 326-334. [CrossRef] [PubMed]

9. McDowell, A.; Perry, A.L.; Lambert, P.A.; Patrick, S. A new phylogenetic group of Propionibacterium acnes. J. Med. Microbiol. 2008, 57, 218-224. [CrossRef] [PubMed]

10. Lomholt, H.B.; Kilian, M. Population genetic analysis of Propionibacterium acnes identifies a subpopulation and epidemic clones associated with acne. PLoS ONE 2010, 5, e12277. [CrossRef] [PubMed]

11. McDowell, A.; Barnard, E.; Nagy, I.; Gao, A.; Tomida, S.; Li, H.; Eady, A.; Cove, J.; Nord, C.E.; Patrick, S. An expanded multilocus sequence typing scheme for Propionibacterium acnes: Investigation of "pathogenic", "commensal" and antibiotic resistant strains. PLoS ONE 2012, 7, e41480. [CrossRef] [PubMed]

12. McDowell, A.; Nagy, I.; Magyari, M.; Barnard, E.; Patrick, S. The opportunistic pathogen Propionibacterium acnes: Insights into typing, human disease, clonal diversification and CAMP factor evolution. PLoS ONE 2013, 8, e70897. [CrossRef] [PubMed]

13. Valanne, S.; McDowell, A.; Ramage, G.; Tunney, M.M.; Einarsson, G.G.; O’Hagan, S.; Wisdom, G.B.; Fairley, D.; Bhatia, A.; Maisonneuve, J.F.; et al. CAMP factor homologues in Propionibacterium acnes: A new protein family differentially expressed by types I and II. Microbiology 2005, 151, 1369-1379. [CrossRef] [PubMed]

14. McDowell, A.; Gao, A.; Barnard, E.; Fink, C.; Murray, P.I.; Dowson, C.G.; Nagy, I.; Lambert, P.A.; Patrick, S. A novel multilocus sequence typing scheme for the opportunistic pathogen Propionibacterium acnes and characterization of type I cell surface-associated antigens. Microbiology 2011, 157, 1990-2003. [CrossRef] [PubMed]

15. Grange, P.A.; Raingeaud, J.; Morelle, W.; Marcelin, A.G.; Calvez, V.; Dupin, N. Characterization of a Propionibacterium acnes surface protein as a fibrinogen-binding protein. Sci. Rep. 2017, 7, 6428. [CrossRef] [PubMed]

16. Eisen, J.A. The RecA protein as a model molecule for molecular systematic studies of bacteria: Comparison of trees of RecAs and 16S rRNAs from the same species. J. Mol. Evol. 1995, 41, 1105-1123. [CrossRef] [PubMed]

17. Palys, T.; Nakamura, L.K.; Cohan, F.M. Discovery and classification of ecological diversity in the bacterial world: The role of DNA sequence data. Int. J. Syst. Evol. Microbiol. 1997, 47, 1145-1156. [CrossRef] [PubMed]

18. Mahenthiralingam, E.; Bischof, J.; Byrne, S.K.; Radomski, C.; Davies, J.E.; Av-Gay, Y.; Vandamme, P. DNA-based diagnostic approaches for identification of Burkholderia cepacia complex, Burkholderia vietnamiensis, Burkholderia multivorans, Burkholderia stabilis, and Burkholderia cepacia genomovars I and III. J. Clin. Microbiol. 2000, 38, 3165-3173. [PubMed]

19. Costechareyre, D.; Rhouma, A.; Lavire, C.; Portier, P.; Chapulliot, D.; Bertolla, F.; Boubaker, A.; Dessaux, Y.; Nesme, X. Rapid and efficient identification of Agrobacterium species by recA allele analysis: Agrobacterium recA diversity. Microb. Ecol. 2010, 60, 862-872. [CrossRef] [PubMed]

20. Stine, O.C.; Sozhamannan, S.; Gou, Q.; Zheng, S.; Morris, J.G., Jr.; Johnson, J.A. Phylogeny of Vibrio cholerae based on recA sequence. Infect. Immun. 2000, 68, 7180-7185. [CrossRef] [PubMed] 
21. Dashtbani-Roozbehani, A.; Bakhshi, B.; Katouli, M.; Pourshafie, M.R. Comparative Sequence analysis of recA gene among Vibrio cholerae isolates from Iran with globally reported sequences. Lett. Appl. Microbiol. 2011, 53, 313-323. [CrossRef] [PubMed]

22. Cooper, J.E.; Feil, E.J. Multilocus sequence typing-What is resolved? Trends Microbiol. 2004, 12, $373-377$. [CrossRef] [PubMed]

23. Rahman, A.; Srivastava, S.S.; Sneh, A.; Ahmed, N.; Krishnasastry, M.V. Molecular characterization of $t l y A$ gene product, Rv1694 of Mycobacterium tuberculosis: A nonconventional haemolysin and a ribosomal RNA methyltransferase. BMC Biochem. 2010, 11, 35. [CrossRef] [PubMed]

24. Aubin, G.G.; Bémer, P.; Kambarev, S.; Patel, N.B.; Lemenand, O.; Caillon, J.; Lawson, P.A.; Corvec, S. Propionibacterium namnetense sp. nov., isolated from a human bone infection. Int. J. Syst. Evol. Microbiol. 2016, 66, 3393-3399. [CrossRef] [PubMed]

25. Kishishita, M.; Ushijima, T.; Ozaki, Y.; Ito, Y. Biotyping of Propionibacterium acnes isolated from normal human facial skin. Appl. Environ. Microbiol. 1979, 38, 585-589. [PubMed]

26. Webster, G.F.; Cummins, C.S. Use of bacteriophage typing to distinguish Propionibacterium acne types I and II. J. Clin. Microbiol. 1978, 7, 84-90. [PubMed]

27. Johnson, J.L.; Cummins, C.S. Cell wall composition and deoxyribonucleic acid similarities among the anaerobic coryneforms, classical propionibacteria, and strains of Arachnia propionica. J. Bacteriol. 1972, 109, 1047-1066. [PubMed]

28. Oprica, C.; Nord, C.E. European surveillance study on the antibiotic susceptibility of Propionibacterium acnes: ESCMID study group on antimicrobial resistance in anaerobic bacteria. Clin. Microbiol. Infect. 2005, 11, 204-213. [CrossRef] [PubMed]

29. Perry, A.L.; Worthington, T.; Hilton, A.C.; Lambert, P.A.; Stirling, A.J.; Elliott, T.S.J. Analysis of clinical isolates of Propionibacterium acnes by optimised RAPD. FEMS Microbiol. Lett. 2003, 228, 51-55. [CrossRef]

30. Sampedro, M.F.; Piper, K.E.; McDowell, A.; Patrick, S.; Mandrekar, J.N.; Rouse, M.S.; Steckelberg, J.M.; Patel, R. Species of Propionibacterium and Propionibacterium acnes phylotypes associated with orthopedic implants. Diagn. Microbiol. Infect. Dis. 2009, 64, 138-145. [CrossRef] [PubMed]

31. Holmberg, A.; Lood, R.; Mörgelin, M.; Söderquist, B.; Holst, E.; Collin, M.; Christensson, B.; Rasmussen, M. Biofilm formation by Propionibacterium acnes is a characteristic of invasive isolates. Clin. Microbiol. Infect. 2009, 15, 787-795. [CrossRef] [PubMed]

32. Niazi, S.A.; Clarke, D.; Do, T.; Gilbert, S.C.; Mannocci, F.; Beighton, D. Propionibacterium acnes and Staphylococcus epidermidis isolated from refractory endodontic lesions are opportunistic pathogens. J. Clin. Microbiol. 2010, 48, 3859-3869. [CrossRef] [PubMed]

33. Niazi, S.A.; Al Kharusi, H.S.; Patel, S.; Bruce, K.; Beighton, D.; Foschi, F.; Mannocci, F. Isolation of Propionibacterium acnes among the microbiota of primary endodontic infections with and without intraoral communication. Clin. Oral Investig. 2016, 20, 2149-2160. [CrossRef] [PubMed]

34. Minegishi, K.; Watanabe, T.; Furukawa, A.; Uchida, K.; Suzuki, Y.; Akashi, T.; Maruyama, F.; Nakagawa, I.; Eishi, Y. Genetic profiles of Propionibacterium acnes and identification of a unique transposon with novel insertion sequences in sarcoid and non-sarcoid isolates. Sci. Rep. 2015, 5, 9832. [CrossRef] [PubMed]

35. Davidsson, S.; Mölling, P.; Rider, J.R.; Unemo, M.; Karlsson, M.G.; Carlsson, J.; Andersson, S.O.; Elgh, F.; Söderquist, B.; Andrén, O. Frequency and typing of Propionibacterium acnes in prostate tissue obtained from men with and without prostate cancer. Infect. Agent Cancer 2016, 11, 26. [CrossRef] [PubMed]

36. Rollason, J.; McDowell, A.; Albert, H.B.; Barnard, E.; Worthington, T.; Hilton, A.C.; Vernallis, A.; Patrick, S.; Elliott, T.; Lambert, P. Genotypic and antimicrobial characterisation of Propionibacterium acnes isolates from surgically excised lumbar disc herniations. Biomed. Res. Int. 2013, 2013, 530382. [CrossRef] [PubMed]

37. Delgado, S.; Suárez, A.; Mayo, B. Identification, typing and characterisation of Propionibacterium strains from healthy mucosa of the human stomach. Int. J. Food Microbiol. 2011, 149, 65-72. [CrossRef] [PubMed]

38. Tomida, S.; Nguyen, L.; Chiu, B.H.; Liu, J.; Sodergren, E.; Weinstock, G.M.; Li, H. Pan-Genome and comparative genome analyses of Propionibacterium acnes reveal its genomic diversity in the healthy and diseased human skin microbiome. mBio 2014, 4, e00003. [CrossRef] [PubMed]

39. Holland, C.; Mak, T.N.; Zimny-Arndt, U.; Schmid, M.; Meyer, T.F.; Jungblut, P.R.; Brüggemann, H. Proteomic identification of secreted proteins of Propionibacterium acnes. BMC Microbiol. 2010, 10, 230. [CrossRef] [PubMed] 
40. Nagy, I.; Pivarcsi, A.; Kis, K.; Koreck, A.; Bodai, L.; McDowell, A.; Seltmann, H.; Patrick, S.; Zouboulis, C.C.; Kemény, L. Propionibacterium acnes and lipopolysaccharide induce the expression of antimicrobial peptides and proinflammatory cytokines/chemokines in human sebocytes. Microbes Infect. 2006, 8, 2195-2205. [CrossRef] [PubMed]

41. Campisano, A.; Ometto, L.; Compant, S.; Pancher, M.; Antonielli, L.; Yousaf, S.; Varotto, C.; Anfora, G.; Pertot, I.; Sessitsch, A.; et al. Interkingdom transfer of the acne-causing agent, Propionibacterium acnes, from human to grapevine. Mol. Biol. Evol. 2014, 31, 1059-1065. [CrossRef] [PubMed]

42. Dekio, I.; Culak, R.; Misra, R.; Gaulton, T.; Fang, M.; Sakamoto, M.; Ohkuma, M.; Oshima, K.; Hattori, M.; Klenk, H.P.; et al. Dissecting the taxonomic heterogeneity within Propionibacterium acnes: Proposal for Propionibacterium acnes subsp. acnes subsp. nov. and Propionibacterium acnes subsp. elongatum subsp. nov. Int. J. Syst. Evol. Microbiol. 2015, 65, 4776-4787. [CrossRef] [PubMed]

43. McDowell, A.; Barnard, E.; Liu, J.; Li, H.; Patrick, S. Emendation of Propionibacterium acnes subsp. acnes (Deiko et al. 2015) and proposal of Propionibacterium acnes type II as Propionibacterium acnes subsp. defendens subsp. nov. Int. J. Syst. Evol. Microbiol. 2016, 66, 5358-5365. [PubMed]

44. Scholz, C.F.; Kilian, M. The natural history of cutaneous propionibacteria, and reclassification of selected species within the genus Propionibacterium to the proposed novel genera Acidipropionibacterium gen. nov., Cutibacterium gen. nov. and Pseudopropionibacterium gen. nov. Int. J. Syst. Evol. Microbiol. 2016, 66, 4422-4432. [CrossRef] [PubMed]

45. Kilian, M.; Scholz, C.F.; Lomholt, H.B. Multilocus sequence typing and phylogenetic analysis of Propionibacterium acnes. J. Clin. Microbiol. 2012, 50, 1158-1165. [CrossRef] [PubMed]

46. Fitz-Gibbon, S.; Tomida, S.; Chiu, B.-H.; Nguyen, L.; Du, C.; Liu, M.; Elashoff, D.; Erfe, M.C.; Loncaric, A.; Kim, J.; et al. Propionibacterium acnes strain populations in the human skin microbiome associated with acne. J. Investig. Dermatol. 2013, 133, 2152-2160. [CrossRef] [PubMed]

47. Robinson, D.A.; Enright, M.C. Evolution of Staphylococcus aureus by large chromosomal replacements. J. Bacteriol. 2004, 186, 1060-1064. [CrossRef] [PubMed]

48. Brochet, M.; Rusniok, C.; Couvé, E.; Dramsi, S.; Poyart, C.; Trieu-Cuot, P.; Kunst, F.; Glaser, P. Shaping a bacterial genome by large chromosomal replacements, the evolutionary history of Streptococcus agalactiae. Proc. Natl. Acad. Sci. USA 2008, 105, 15961-15966. [CrossRef] [PubMed]

49. Brüggemann, H.; Lomholt, H.B.; Kilian, M. The flexible gene pool of Propionibacterium acnes. Mob. Genet. Elem. 2012, 2, 145-148. [CrossRef] [PubMed]

50. Brzuszkiewicz, E.; Weiner, J.; Wollherr, A.; Thürmer, A.; Hüpeden, J.; Lomholt, H.B.; Kilian, M.; Gottschalk, G.; Daniel, R.; Mollenkopf, H.J.; et al. Comparative genomics and transcriptomics of Propionibacterium acnes. PLoS ONE 2011, 6, e21581. [CrossRef] [PubMed]

51. Spratt, B.G.; Maiden, M.C.J. Bacterial population genetics, evolution and epidemiology. Philos. Trans. R. Soc. Lond. B 1999, 354, 701-710. [CrossRef] [PubMed]

52. Brüggemann, H.; Lomholt, H.B.; Tettelin, H.; Kilian, M. CRISPR/cas Loci of type II Propionibacterium acnes confer immunity against acquisition of mobile elements present in type I P. acnes. PLoS ONE 2012, 7, e34171. [CrossRef] [PubMed]

53. Multi Locus Sequence Typing. Available online: http:// pacnes.mlst.net/ (accessed on 19 December 2017).

54. Propionibacterium acnes MLST Databases. Available online: https://pubmlst.org/pacnes (accessed on 19 December 2017).

55. Urwin, R.; Maiden, M.C.J. Multi-locus sequence typing: A tool for global epidemiology. Trends Microbiol. 2003, 11, 479-487. [CrossRef] [PubMed]

56. Feil, E.J.; Li, B.C.; Aanensen, D.M.; Hanage, W.P.; Spratt, B.G. eBURST: Inferring patterns of evolutionary descent among clusters of related bacterial genotypes from multilocus sequence typing data. J. Bacteriol. 2004, 186, 1518-1530. [CrossRef] [PubMed]

57. Davidsson, S.; Söderquist, B.; Elgh, F.; Olsson, J.; Andrén, O.; Unemo, M.; Mölling, P. Multilocus sequence typing and repetitive-sequence-based PCR (DiversiLab) for molecular epidemiological characterization of Propionibacterium acnes isolates of heterogeneous origin. Anaerobe 2012, 18, 392-399. [CrossRef] [PubMed]

58. Shannon, B.A.; Cohen, R.J.; Garrett, K.L. Polymerase chain reaction-based identification of Propionibacterium acnes types isolated from the male urinary tract: Evaluation of adolescents, normal adults and men with prostatic pathology. BJU Int. 2006, 98, 388-392. [CrossRef] [PubMed] 
59. Barnard, E.; Nagy, I.; Hunyadkürti, J.; Patrick, S.; McDowell, A. Multiplex touchdown PCR for rapid typing of the opportunistic pathogen Propionibacterium acnes. J. Clin. Microbiol. 2015, 53, 1149-1155. [CrossRef] [PubMed]

60. Lheure, C.; Grange, P.A.; Ollagnier, G.; Morand, P.; Désiré, N.; Sayon, S.; Corvec, S.; Raingeaud, J.; Marcelin, A.G.; Calvez, V.; et al. TLR-2 recognizes Propionibacterium acnes CAMP Factor 1 from highly inflammatory strains. PLoS ONE 2016, 11, e0167237. [CrossRef] [PubMed]

61. Paugam, C.; Corvec, S.; Saint-Jean, M.; Le Moigne, M.; Khammari, A.; Boisrobert, A.; Nguyen, J.M.; Gaultier, A.; Dréno, B. Propionibacterium acnes phylotypes and acne severity: An observational prospective study. J. Eur. Acad. Dermatol. Venereol. 2017, 9, e398-e399. [CrossRef] [PubMed]

62. Cebrián, R.; Arévalo, S.; Arias-Santiago, S.; Riazzo, C.; Rojo, M.D.; Bermúdez, P.; Valdivia, E.; Martínez-Bueno, M.; Maqueda, M. Optimization of genotypic and biochemical methods to profile P. acnes isolates from a patient population. J. Microbiol. Methods 2017, 141, 17-24. [CrossRef] [PubMed]

63. Barnard, E.; Liu, J.; Yankova, E.; Cavalcanti, S.M.; Magalhães, M.; Li, H.; Patrick, S.; McDowell, A. Strains of the Propionibacterium acnes type III lineage are associated with the skin condition progressive macular hypomelanosis. Sci. Rep. 2016, 6, 3196. [CrossRef] [PubMed]

64. Capoor, M.N.; Ruzicka, F.; Schmitz, J.E.; James, G.A.; Machackova, T.; Jancalek, R.; Smrcka, M.; Lipina, R.; Ahmed, F.S.; Alamin, T.F.; et al. Propionibacterium acnes biofilm is present in intervertebral discs of patients undergoing microdiscectomy. PLoS ONE 2017, 12, e0174518. [CrossRef] [PubMed]

65. Burnham, J.P.; Shupe, A.; Burnham, C.D.; Warren, D.K. Utility of strain typing of Propionibacterium acnes in central nervous system and prosthetic joint infections to differentiate contamination from infection: A retrospective cohort. Eur. J. Clin. Microbiol. Infect. Dis. 2017. [CrossRef] [PubMed]

66. Patrick, S.; McDowell, A.; Lee, A.; Frau, A.; Martin, U.; Gardner, E.; McLorinan, G.; Eames, N. Antisepsis of the skin before spinal surgery with povidone iodine-alcohol followed by chlorhexidine gluconate-alcohol versus povidone iodine-alcohol applied twice for the prevention of contamination of the wound by bacteria: A randomised controlled trial. Bone Jt. J. 2017, 99-B, 1354-1365. [CrossRef] [PubMed]

67. Scholz, C.F.P.; Jensen, A.; Lomholt, H.B.; Brüggemann, H.; Kilian, M. A novel high-resolution single locus sequence typing scheme for mixed populations of Propionibacterium acnes in vivo. PLoS ONE 2014, 9, e104199. [CrossRef] [PubMed]

68. SLST for Cutibacterium acnes (formerly Propionibacterium acnes). Available online: http://medbac.dk/slst/ pacnes (accessed on 19 December 2017).

69. Petersen, R.L.; Scholz, C.F.; Jensen, A.; Brüggemann, H.; Lomholt, H.B. Propionibacterium acnes phylogenetic type III is associated with progressive macular hypomelanosis. Eur. J. Microbiol. Immunol. 2017, 7, $37-45$. [CrossRef] [PubMed]

70. Hauck, Y.; Soler, C.; Gérôme, P.; Vong, R.; Macnab, C.; Appere, G.; Vergnaud, G.; Pourcel, C. A novel multiple locus variable number of tandem repeat (VNTR) analysis (MLVA) method for Propionibacterium acnes. Infect. Genet. Evol. 2015, 33, 233-241. [CrossRef] [PubMed]

71. Sabat, A.J.; Budimir, A.; Nashev, D.; Sá-Leão, R.; van Dijl, J.M.; Laurent, F.; Grundmann, H.; Friedrich, A.W. ESCMID Study Group of Epidemiological Markers (ESGEM). Overview of molecular typing methods for outbreak detection and epidemiological surveillance. Euro Surveill. 2013, 18, 20380. [CrossRef] [PubMed]

72. MLVAbank for Microbes Genotyping. Available online: http://microbesgenotyping.i2bc.paris-saclay.fr/ (accessed on 19 December 2017).

73. Park, K.H.; Greenwood-Quaintance, K.E.; Uhl, J.R.; Cunningham, S.A.; Chia, N.; Jeraldo, P.R.; Sampathkumar, P.; Nelson, H.; Patel, R. Molecular epidemiology of Staphylococcus aureus bacteremia in a single large Minnesota medical center in 2015 as assessed using MLST, core genome MLST and spa typing. PLoS ONE 2017, 12, e0179003. [CrossRef] [PubMed]

74. Dominguez, S.R.; Anderson, L.J.; Kotter, C.V.; Littlehorn, C.A.; Arms, L.E.; Dowell, E.; Todd, J.K.; Frank, D.N. Comparison of whole-genome sequencing and molecular-epidemiological techniques for Clostridium difficile strain typing. J. Pediatr. Infect. Dis. Soc. 2016, 5, 329-332. [CrossRef] [PubMed]

75. Maiden, M.C.; Jansen van Rensburg, M.J.; Bray, J.E.; Earle, S.G.; Ford, S.A.; Jolley, K.A.; McCarthy, N.D. MLST revisited: The gene-by-gene approach to bacterial genomics. Nat. Rev. Microbiol. 2013, 11, 728-736. [CrossRef] [PubMed]

76. Cutibacterium acnes. Available online: https://www.ncbi.nlm.nih.gov/genome/?term=acnes (accessed on 19 December 2017). 
77. Jolley, K.A.; Maiden, M.C.J. BIGSdb: Scalable analysis of bacterial genome variation at the population level. BMC Bioinform. 2010, 11, 595. [CrossRef] [PubMed]

78. Keith Jolley. Bacterial Isolate Genome Sequence Database (BIGSdb). Available online: http://pubmlst.org/ software/database/bigsdb/ (accessed on 19 December 2017).

79. Centre for Genomic Epidemiology. Available online: https://cge.cbs.dtu.dk/services/MLST (accessed on 19 December 2017). 